\title{
La fiesta de san Caralampio. ETNOGRAFÍA DE UN ESPACIO SOCIAL
}

\author{
Jesús Solís Cruz \\ Rosario Culebro Alfaro
}

I

L

a convocatoria se hizo con mucha antelación, incluso antecede a quienes estamos en el evento, mismo al cual asisten invitados y quienes de "oídas" o por la fuerza de la costumbre siempre han acudido. La motivación que mueve a la asistencia puede variar según sea el participante. Lo que no varía es el motivo: venerar a uno de los santos más importantes de la región: san Caralampio. El lugar de reunión no sabemos en qué fecha fue consensado, lo que sí sabemos es que en esta fecha se cita gran número de personas de toda la región. Es un cruce de camino el que comunica a la ciudad mestiza de Comitán con sus ejidos y comunidades. El punto de referencia: un árbol; conocido en la región como chumish. Aquí, desde muy temprano por la mañana hasta el mediodía llegan de la ciudad de Comitán en numerosos y variados contingentes, personas disfrazadas formando caravanas de "demonios, de señoritas bien, de guerrilleros”, entre ellos incluso persona-

Jesús Solís Cruz, Centro de Estudios Superiores de México y Centroamérica, UNICACH.

Rosario Culebro Alfaro, becaria en el proyecto financiado por el CONACYT, a cargo de la doctora Mercedes Olivera. jes ilustres de la historia mexicana reciente: juntos se pueden ver al presidente de la república en turno con otros personajes de igual significancia política: "Carlos Salinas de Gortari, Ernesto Zedillo, Vicente Fox, Tatic Samuel Ruiz, Fidel Castro..." unos y otros solemne y ceremoniosamente agitando la mano, reafirmando su investidura y su lugar en la posteridad. No sin menor solemnidad, se congregan indígenas tojolabales y campesinos mestizos de los ejidos y comunidades vecinas de los Valles de Comitán, algunos de ellos evidenciando sus posiciones religiosas portan banderas con efigies alusivas, otros provistos con pitos y tambor, todos debidamente aprovisionados de sus bastimentos, al lado y con poca incidencia las mujeres de algunos de ellos.

Para algunos el acontecimiento es el carnaval de san Caralampio, para otros la romería o entrada de flores al santo, para muchos otros la fiesta. Al final, en todos los participantes está presente este último elemento: el festejo, la fiesta, su significado es unívoco aunque su representación es diversa: religioso-sagrado; pagano-profano. Su sentido unívoco es la vida, es el punto de confluencia en este universo variopinto que es la fiesta de san Caralampio. 
Para desenmarañar y alcanzar algún grado de entendimiento de esta red de sentidos múltiples, es preciso situar el lugar y las consideraciones desde las que estamos partiendo. En principio conviene decir que entendemos la fiesta de san Caralampio como un espacio de múltiples encuentros, un espacio que es construido en la interacción social. Es decir, un espacio construido con base en relaciones sociales diversas, mediadas de relaciones de poder, poniendo en escena fronteras sociales, étnicas, políticas, culturales (Lefebvre, 1991; Bourque, 1997; Hoffman y Salmerón, 1997; Velásquez, 1997; De la Fuente, 2002).

Partimos de caracterizar este acontecimiento como una "fiesta", porque en esta caracterización se enmarca la "convención que concibe que la fiesta - la celebración, la acción festiva - es una expresión de carácter simbólico relacionada, en forma relativa, con la naturaleza social, la posición estructural de los individuos en un presente, y los antecedentes o proveniencia histórica y cultural del grupo o del conjunto social que la realiza" (Lameiras, 1998:173). En este mismo sentido, como ya lo hemos apuntado, es un festejo, es la fiesta de la vida, en sus dos variantes: sagrado-religioso/profanopagano. Por un lado, y como lo explicaremos más adelante, los "romeristas o participantes en la entrada de flores" en la figura de los indígenas y campesinos, agradecen, celebran y conmemoran la desaparición de una peste y la estabilidad y permanencia en esta vida; por otro lado los "enmascarados", protagonizados por los citadinos comitecos, en este día que se convierte en un día "feriado" en la ciudad de Comitán, un día libre, se disponen a la juerga y al jolgorio, aquí también como lo señala Da Matta (2002) para el caso brasileño, es un momento extraordinario marcado por la alegría y por el rompimiento de la rutina. Así, en esta fiesta en un espacio físico y temporal se rompe con la cotidianeidad. Se construye y se apropia de este modo un espacio social.

Intentamos un mejor acercamiento e interpretación, pues creemos que la fiesta como construcción social en el espacio físico y en el tiempo es también un acto ritual. Rescatamos en este sentido la preocupación de Edmund Leach cuando señala que "la acción ritual y la creencia deben entenderse igualmente como formas de exposición simbólica del orden social. (...) La estructura que se simboliza en el ritual es el sistema socialmente aprobado de relaciones "adecuadas" entre los individuos y entre los grupos. (...) ...si ha de evitarse la anarquía, los individuos que constituyen una sociedad deben recordar de vez en cuando, por lo menos en forma de símbolo, el orden subyacente que se supone que guía sus actividades sociales" (1976: 36-38).

De suyo polimorfa y de múltiples significados ("cada quien habla de cómo le fue en la fiesta"), lo que intentaremos aquí es fundamentalmente un entendimiento de la fiesta como espacio social en continua construcción, que nos revela, "dramatiza" o expone simbólicamente estructuras sociales (Leach, 1976; Turner, 1999). Es preciso adelantar que la fiesta de san Caralampio tiene un calendario amplio. Aquí nos remitimos a observar un solo día y tres momentos en el desarrollo del ritual. El día, 10 de febrero, es en el que confluyen los "enmascarados, disfrazados" con los "romeristas o participantes en la entrada de flores", los momentos son: el punto de reunión (el árbol de chumish) y el trayecto en la calle hacia el templo de san Caralampio. Existe un tercer momento, el arribo al templo de san Caralampio, este también es muy significativo en cuanto a las conductas y valores sociales movilizados en ese momento y espacio, 
sin embargo, nos parece que merece una atención especial por otros factores tan diversos que se entrelazan (políticos, económicos...). Después de observar y registrar durante cinco años este día (1998-2002), hemos arribado a la determinación de ubicar estos tres momentos (dos de ellos aquí analizados) y este día como "dramatizadores, escenificadores" de estructuras sociales de los participantes en esta fiesta. Valga antes algunos datos históricos y generales que nos procuren un entendimiento mayor de la fiesta.

\section{II}

La fiesta en honor a san Caralampio tiene lugar cada año en la ciudad fronteriza de Comitán de Domínguez, en el municipio del mismo nombre. Esta ciudad es una de las más importantes en el estado de Chiapas; administrativamente es cabecera distrital dentro de la región III, denominada Fronteriza. La región está conformada por ocho municipios: La Trinitaria, Las Margaritas, Tzimol, Socoltenango, Frontera Comalapa, La Independencia, Chicomuselo y Comitán.

Comitán se conformó como un pueblo de indios y fue producto de las congregaciones llevadas a cabo por los dominicos. Fue el asiento de españoles y de misioneros, así como centro rector económico a partir de la fundación de haciendas, la mayoría de ellas, en manos de los dominicos, en los llanos pertenecientes a este pueblo. Es a partir de aquí hasta el periodo de desamortización de los bienes de la Iglesia que fue un centro rector económico de gran importancia. Las haciendas propiedad de dominicos y algunas de españoles fueron las que dominaron la estructura agraria de este municipio hasta bien entrado el siglo xx. Su gobierno estaba sustentado en el cabildo indígena hasta el año de la entrada en vigor de las leyes de Cádiz (1812) y es justamente en este marco que los españoles y mestizos quitaron el poder político a los indígenas para situarse como rectores de la vida política, aunque en el ámbito de la economía ya predominaban desde antes (Ruz, 1992).

$\mathrm{Al}$ amparo de las leyes de Cádiz y de las Leyes de Reforma muchos españoles y mestizos pudieron ampliar sus propiedades y ejercer un dominio político y económico mayor sobre la población indígena.

Comitán gradualmente pasa de ser un pueblo de indios a un pueblo compuesto por mestizos y españoles. Comienza a caracterizarse como un municipio finquero; según esta caracterización de Araceli Burguete un municipio compuesto por un cinturón de pueblos y comunidades indígenas y una cabecera ocupada (política y económicamente) mayoritariamente por mestizos (comunicación personal con Araceli Burguete Cal y Mayor 2002).

En todo este contexto se funda la adoración a san Caralampio. Según la historia oral, la celebración de la fiesta de san Caralampio es producto del agradecimiento que los habitantes de la denominada región de Los Llanos de Comitán, tienen a este santo por la protección en años aciagos. Azotada por la peste, la región había sido grandemente diezmada desde principios del siglo XVII (Ruz, 1992). Hacia mediados del siglo XIX se registra la existencia de una nueva peste que estaba diezmando a la población. En este ambiente se hace notable la presencia de la figura del mártir san Caralampio. Aunque existen versiones distintas en cuanto a la procedencia y presencia del santo en la región, la que más ha gozado de aceptación es la que señala que la efigie fue adquirida a través de una compra a un soldado por un importante finquero de la región. Otras versiones, si acaso más 
recientes, señalan que la efigie fue traída de Guatemala entre los bastimentos de un viajero comerciante, y se quedó en los dominios de uno de los hacendados más prósperos de los valles de Comitán (Solís y Culebro, 2002). Se narra que el hacendado pidió protección divina al mártir san Caralampio contra la peste. Ante el auxilio y protección atribuida al santo, al conocerse la inexistencia de la amenaza de la peste en la hacienda, los vecinos del entonces pueblo de Comitán y los trabajadores de la hacienda en respuesta a tan divina obra, encabezados por el hacendado propietario de la imagen del santo, iniciaron la construcción de un templo en honor del dicho santo en el pueblo de Comitán. (Solís y Culebro, 2002) El templo se construyó bajo la gestoría del hacendado don Raymundo Solís en el barrio de La Pila entre los años de 1852 y 1855, y fue en el año de 1862 por decreto del gobernador cuando se instituyó la fiesta comercial de san Caralampio. El de Carlos Navarrete (1990) sigue siendo el trabajo más completo e imprescindible.

Son importantes algunas observaciones a este contexto que hemos descrito. Por principio, que son coincidentes el momento en que son desamortizados los bienes de la Iglesia y aquel en que algunos de los más pudientes finqueros logran expandir sus propiedades y dominio político sobre las comunidades indígenas. Es además, la oportunidad de otros mestizos de conquistar poder político y de asegurar propiedades, consolidándose de este modo de una manera más férrea la relación de patronaje en la región. Es preciso decir aquí que buena parte de la vida social de los habitantes de las actuales comunidades indígenas y ejidos de la región fue dominada por la finca (véase Ruz, 1992; Gómez y Ruz, 1992). Muchos de los nuevos y viejos patrones asumían representaciones diversas ante sus peones, entre ellas la de rectores espi- rituales y cristianizadores. Conviene decir también, que el sentimiento político liberal que privaba en ese momento estaba fuertemente cargado a impulsar la creación de una república que sustentara su desarrollo en la modernidad (política, social y económica); es decir, según este proyecto se intentaba la ruptura con atavismos y erradicación de vicios, de allí que se idearan leyes para encauzar a las "clases ociosas" a incorporarse a este proyecto modernizador. En este contexto los patrones de las fincas jugaron un papel importante, encontraron cobijo en este ambiente para consolidar prácticas de explotación más efectivas.

Otra cuestión que es de igual trascendencia que la anterior tiene que ver con la creciente importancia económica de la región de los valles de Comitán en el estado de Chiapas. Es indicativo para el caso que aquí nos ocupa, cómo la institucionalización de la fiesta de san Caralampio se da en el reconocimiento de la región como una de las más destacadas económicamente. Mario Humberto Ruz señala al respecto: "No deja de ser interesante observar los profundos cambios que se operaron entre el Comitán de 1785, cuando fenecía el sistema de alcaldías que tanto había privilegiado a Ciudad Real (San Cristóbal de Las Casas), y el de 1862, año en el cual la región comiteca mostraba ya claros signos del papel rector que vendría a jugar en la zona limítrofe entre Chiapas y Guatemala, (...) A más de su notorio incremento demográfico (con $35.6 \%$ de población 'ladina') y el alto monto de sus contribuciones a la economía estatal, el 'despegue’ de la antigua Balún Canán puede también observarse al comparar lo registrado en ambos años acerca de los 'oficios' que ejercían los comitecos, ...” (Ruz, 1992:304).

Es decir, no es fortuita la asignación oficial de la celebración comercial de la fiesta de san 
Caralampio y el naciente fervor al mismo santo. A esto se sumarían conductas culturales de los habitantes, manifiestas en la veneración religiosa.

Así, con la atribución de una protección divina a las propiedades del hacendado, la fama que alcanzó el mártir san Caralampio llegó hasta las tierras de los vecinos habitantes de Guatemala. Aún hoy es posible observar la concurrencia a la celebración de habitantes de los vecinos pueblos de Chiapas y Guatemala. Edificada en la adversidad, esta fama del mártir se montó sobre una estructura de relación social fundada en el acasillamiento en las haciendas (Solís y Culebro, 2002).

De acuerdo con la historia oral, la celebración al mártir san Caralampio desde sus inicios se ha mantenido con los componentes que hoy la caracterizan: "romeristas (entradas de flores) y enmascarados (carnaval)".

Las variaciones se encuentran en las representaciones de esta conmemoración, así como en las relaciones sociales. En lo que hemos podido conocer de esta celebración en el transcurso del tiempo, no únicamente remitido a nuestra observación profesional, sino además a nuestra propia vivencia, hemos observado por lo menos dos cambios fundamentales, uno de ellos tiene que ver con el arribo en la ultima década de una discursividad y práctica que rescata la preeminencia del carácter sagrado-religioso indígena de la celebración, desde los mismos indígenas y campesinos participantes. En años anteriores a 1995 los "romeristas" realizaban su entrada de flores por la tarde, mientras que el carnaval se realizaba como aún continua, por la mañana. Una de las explicaciones "prácticas" de los participantes en la entrada de flores para trasladar la celebración a la mañana, es la falta de transporte que los llevará de regreso a sus localidades por la tarde, creemos que junto a esta ex- plicación existe una más que se asocia con la puesta en la escena política de la trascendencia de la cultura indígena. Aquí creemos que la politización hacia las comunidades es de gran trascendencia para buscar ocupar un espacio de mayor incidencia en la escena pública, es importante decir que muchas de estas comunidades y ejidos han cobijado y recreado el trabajo organizativo de la Diócesis de San Cristóbal de Las Casas, desde donde se remarca justamente la importancia de los patrones culturales y sociales indígenas.

El otro cambio asociado con el anterior, tiene que ver con el lugar cedido a la romería o entrada de flores, por instituciones oficiales y no oficiales, así como por intelectuales comprometidos con el rescate cultural, como un espacio de expresión primigenia de la cultura indígena. Estos cambios están asociados con acontecimientos sociales y políticos más amplios que buscan rescatar y situar la cultura indígena como un valor moral preeminente, idealizando estructuras organizativas y patrones culturales comunitaristas dando pie en muchas ocasiones a acciones sociales cargadas de intolerancia. En este contexto la religión es sólo una de las dimensiones en que se expresan estas acciones intolerantes.

Aquí nos ocupamos no de rescatar imágenes primigenias indianistas, sino de intentar una lectura que muestre estructuras históricas sociales cambiantes y en permanente recomposición y resignificación. Esa es la meta de este trabajo.

\section{III El punto de encuentro}

El momento puede ser un juego de máscaras: aquí un maquillaje que revela a un caníbal con un trozo de carne en la mano dominado y controlado 
por medio de una cadena por un cazador, allá un par de "señoritas" que se descubren o encubren en una máscara de dama de finas facciones, tocadas bellamente con un sombrero de paja y con un abanico en la mano que aminora el cada vez mas sofocante calor; más allá un par de "diputados" que cartera en mano dispensan bienes a los desvalidos, jinetes o charros que haciendo gala de sus mejores trajes y caballos traen en ancas de sus caballos bellas "charras"; junto a ellos un "Pokemon" que en su desesperación por la carga de su vestimenta se desviste para refrescarse con un raspado de hielo aderezado con "temperante" . Muy cerca del árbol y junto a la cruz, en una pequeña cima, se halla un grupo de tojolabales y campesinos, que al resguardo de sus estandartes y de la sombra quienes procuran el árbol de chumish descubren sus cabezas para inclinarse y saludar otras banderas que en distintas letras revelan la procedencia de cada grupo que las porta: unas del ejido de El Señor de los Pozos, otras de los tojolabales de la comunidad Veinte de Noviembre, otra del barrio comiteco de El Cerrito. Todos están hacia el medio día en el umbral de la ciudad y en el inicio de su trayecto hacia el templo de su santo en veneración.

Antes de este momento el lugar físico no nos representaba más que un cruce de camino, el umbral entre la ciudad y las comunidades y ejidos. Sin embargo, el día acordado con tanta antelación que escapa a la memoria de los participantes, ya ha significado al árbol de chumish y a la cruz que junto a él se encuentra. Es el 10 de febrero y aunque el año lo hemos visto variar, el sitio o espacio físico es el mismo. Casi invariablemente el arribo a este punto es a las nueve de la mañana, y es casi invariable también que quienes primero se apostan en el lugar son los comer- ciantes de comidas y bebidas. Conforme transcurren las horas el espacio se va poblando.

Alrededor de las once la mañana, en la cruz de madera que se halla sobre una base de concreto construida a su vez sobre una pequeña loma que está junto al árbol, pero que vista desde la dirección en que entran los habitantes de las comunidades hacia la ciudad es el frente, se pueden observar por lo menos tres estandartes simbolizando distintos santos. Éstos, así como los que habrán de arribar en manos de sus portadores serán objeto de un breve ritual. Se postran enfrente de la cruz y descubren sus cabezas del tocado que porten (sombrero o gorra), después uno a uno de los portadores del estandarte harán una cruz en su frente y besarán los estandartes ya colocados. La forma en que están dispuestos los estandartes obedece a una jerarquía: del lado izquierdo las banderas de menor rango, del lado derecho las de rango mayor. ${ }^{2}$

Visiblemente y sin mayor detenimiento podemos decir que es el punto en donde confluyen parias con notables, el bien y el mal, la razón con la sinrazón. Es también, sin duda para todos, el día de fiesta, el momento en donde se abren las posibilidades de expresión, el momento de límites y de desahogos. Es de igual modo, si nos detenemos a observar con mayor detalle, el momento en que se ponen en escena valores y patrones sociales de los participantes. Aun cuando parece contradictorio, este paisaje tan diverso y desestructurado en que se nos presenta esta fiesta, mantiene una estructura y ordenamiento.

El lugar físico se va estructurando socialmente conforme se congregan el número estimado de personas participantes. Vemos en un extremo a los tamboreros y piteros venidos de las comunidades y ejidos. Reunidos en círculo, desde el momento en que se han presentado los ejecutores de los dos 
instrumentos característicos de este momento, de cualquier comunidad: pito y tambor, la música no cesa. Mientras, junto a este grupo se encuentran representantes religiosos comunitarios, cuando éstos no comparten la categoría de músico o "pitero o tamborero"; se hallan hacia ese mismo extremo — junto al árbol de cbumish o junto a la cruz- las demás personas venidas de las comunidades y ejidos. Es notorio que quienes ejecutan estos instrumentos musicales todos son hombres y de edad adulta. La mayoría de ellos se describen como profundos conocedores de la tradición en la ejecución de su instrumento - ya sea pito o tambory en muchos de los casos orgullosos por haber accedido a él vía hereditaria, ya a través del padre o algún pariente. Los pocos casos no heredados afirman su acceso por su virtuosidad en la ejecución o por "encomienda de la comunidad". Los valores morales y culturales que rigen las estructuras sociales de los habitantes de estas comunidades son de este modo puestas en escena en la celebración: virtuosidad, herencia, edad y asignación de responsabilidades venidas de la mayoría comunitaria, todo en un ambiente permeado por la influencia masculina. ${ }^{3}$

Hacia el extremo opuesto se hallan los enmascarados y demás espectadores. Entre ellos invariablemente año con año existe un grupo marimbístico que ameniza el baile, en ocasiones algunos de los participantes conducen coches o camionetas que cargan portentosas bocinas y aparatos que reproducen música de moda. Aquí es notorio que en el círculo formado por los piteros y tamboreros no existe intromisión o inclusión de enmascarados o disfrazados a excepción del "diablo". Este es el único personaje "liminal" (Turner, 1999) que puede moverse en este espacio entre lo sagrado y lo profano, lo solemne y rijoso, puede meterse y bailar en el círculo formado por los piteros y tamboreros. Tiene este personaje la característica de estar en el trance permanente, es liminal en un momento ritualizado y veremos cómo en la siguiente fase del desarrollo de la fiesta mantiene esta característica "liminal" (Turner, 1999).

En el resto del espacio algunos gozando del uso de "su investidura" puede dispensar bendiciones ("Tatic Samuel Ruiz") o bienes materiales ("un diputado, ataviado con traje y corbata, lentes oscuros, pulsera y cadenas de oro: portafolio y billete en mano reparte la riqueza al pueblo") circulando junto al caníbal, junto a la prostituta o junto a algún personaje de alguna película norteaméricana (Rambo, Spiderman). En esta vertiente de la fiesta se congregan los personajes más disímiles: Samuel Ruiz /Vicente Fox /Zedillo / Marcos / Bin Laden; la prostituta/la señorita refinada (cotorra o quedada)/ la señora de casa gorda, desaliñada y llena de hijos; Rambo/Piolín/Spiderman/Caníbal/ Cazador. El sentido carnavalesco lo ha visto Efraín Ascencio (2000).

Es la sátira del orden pero es también la escenificación de los valores morales y conductas que guardan una relación con lo privado. Este es el momento en que este ámbito es expuesto al espacio público. Cercanos a la apreciación que $\mathrm{Da}$ Matta (2002) realiza para el caso de Brasil, aquí también creemos que existe un proceso de doble vuelta: la casa es invadida por la calle, al igual que la calle invade la casa. En la siguiente fase a describir veremos cómo esta situación se vuelve más evidente.

Las figuras femeninas son casi por regla general personificadas por hombres, mientras que las masculinas por mujeres. Se intenta romper con esquemas sociales que en la cotidianidad no podrían ser enjuiciados de esa manera sin ser fuertemente descalificados. Aquí la "señorita" puede 
tener juegos sexuales simbólicos con el diablo, flirtear con Rambo o incluso con Piolín o Spiderman. Al igual que Samuel Ruiz puede tener juegos sexuales con la prostituta o entablar y estrechar amistad con Fox, Zedillo o Marcos. Se satirizan y transgreden órdenes pero también se posibilitan y escenifican valores morales que subyacen en la sociedad. Se traspasa el ámbito de lo privado para mostrar y recordar que allí están presentes valores y patrones sociales y culturales de esa sociedad participante.

En este espacio se genera así un flujo permanente de ideologías, de papeles sociales, de posiciones de poder que van situando a los actores en espacios delimitados.

\section{IV El trayecto en la calle}

Ir del punto de encuentro hacia la calle para iniciar el trayecto hacia el templo de san Caralampio es otro momento que requiere de la movilización de todas las estructuras ya descritas antes y la escenificación o representación de otras. Quienes inician y marcan la pauta son los "encargados de iglesia" de las comunidades y ejidos participantes. Cuando se han reunido todos los representantes, toma la iniciativa de organizar el trayecto la persona que ha sido nombrada con antelación para coordinar este y los otros eventos. En este caso es don Rubén García, quien se encarga de vigilar la disposición correcta de los estandartes de acuerdo con el criterio ya mencionado (nota número 2). Don Rubén es entre los demás participantes del festejo a san Caralampio, el coordinador de las actividades y reuniones habidas y por haber para efectuar las demás celebraciones religiosas de acuerdo con el calendario religioso de la región. Es importante notar que don Rubén fue nombrado coordinador general de estas celebraciones desde hace once años, y entre los criterios que privaron para elegirlo rigen principios morales y culturales que atraviesan y controlan la estructura organizativa o directora de los cargos religiosos: honradez, responsabilidad, edad, sexo (masculino); es decir, honor, lealtad (hacia sus vecinos como hacia Dios y su religión), experiencia (edad). Reconocidos todos estos valores en la persona de los "encargados" de cada iglesia comunitaria, el conjunto de estos "encargados" con todo ese valor moral, selecciona a una persona, bien entre el mismo grupo de participantes de las celebraciones de todo el calendario religioso, o bien de sus comunidades o ejidos que reúna esos mismo valores para que los coordine en todas las actividades a realizar durante sus celebraciones. Las actividades y funciones de este "representante presidente" van desde ser correa de transmisión de notificaciones venidas de los funcionarios eclesiásticos, hasta coordinar un evento como la fiesta.

Así, una vez reunidos todos los representantes religiosos comunitarios y ejidales, "el presidente" instruye el orden de los estandartes en la calle. A la derecha los estandartes que simbolizan los santos más importantes, por el lado izquierdo los de menor importancia. Entre la multitud agolpada en la calle los representantes se colocan al frente de lo que será el contingente. Una vez dispuestos los estandartes de acuerdo con el orden establecido unos y otros se rinden homenaje. Todos los portadores de estandarte deben besar y limpiar sus rostros en cada uno de los estandartes presentes. Una vez hecho esto, inician la marcha hacia el templo de san Caralampio. La marcha toma la calle principal que comunica el espacio rural con la ciudad. Toda la calle se encuentra adornada con motivos festivos y se encuentra llena de espectadores. 
Vale decir en este punto que el encabezamiento de la celebración por parte de los representantes religiosos es reciente, si acaso seis o siete años y tiene que ver, como lo apuntamos antes, con la revaloración y autopercepción por parte de los participantes de las comunidades y ejidos, así como de promotores y simpatizantes culturalistas, del carácter religioso cultural indígena de la celebración, argumentando una tradición primigenia indígena. Antaño esta celebración era encabezada por los "disfrazados o enmascarados". Esta inversión en el orden de la estructura de la celebración, y el cambio en la relación social que refleja, en el caso particular, deviene en tensión, tuvimos oportunidad de observarla al inicio de la marcha hacia la ciudad en el año 2001. Fue en ese momento cuando los jinetes o charros mestizos de la ciudad quisieron encabezar la marcha. En un alegato que argumentaba otorgar mayor atracción visual al festejo, los jinetes se posicionaron al frente del contingente que ya había comenzado su marcha; ante esta situación el "presidente" representante de las comunidades y ejidos —en un contraalegato formulado a partir de la continuidad histórica y el tradicionalismo de la festividad - argumentó que encabezarían la celebración por ser ellos "los meros interesados en agradecer al santo, los que mero llevan la religión como debe ser". Ante tal situación, los tamboreros y piteros, así como los representantes portadores de los estandartes, disputaron el espacio en una buena parte del recorrido.

Ante la persistencia de los representantes religiosos comunitarios, los jinetes en ocasiones en medio del contingente, en otras al frente, no tuvieron más opción que ceder el espacio. Así, los representantes de las comunidades y ejidos se posicionaron al frente (Solís y Culebro, 2002).
El contingente que marcha hacia el templo recrea así estructuras y conductas sociales y culturales. Al frente en el contingente van los portadores de los estandartes ${ }^{5}$, alineados en los laterales de la calle los estandartes, en medio las mujeres de los portadores de estandartes, así como demás hombres y mujeres venidos de las comunidades y ejidos, todos llevan ramos de flores silvestres. Al frente de este grupo que camina en medio de los estandartes, una mujer mestiza comiteca se encarga de los cánticos y rezos al santo. Es esta la única mujer que tiene destacada participación en esta fase de la celebración, y es asimismo la única persona que se encarga en todas las celebraciones del calendario ritual de llevar a efecto los rezos y cánticos. ${ }^{6}$ Atrás de este primer contingente vienen los tamboreros y piteros. Atrás de éstos los disfrazados o enmascarados. Es el día en que también, la reina de la fiesta comercial de san Caralampio sale a pasearse y exhibirse.

La radio local traslada de igual modo su espacio cerrado hacia el lugar abierto. Desde la calle se trasmite la fiesta hacia el "interior de los hogares". La fiesta se mete a la casa, la casa sale a la calle. En tanto la gente deja su espacio privado de la casa abierto hacia la calle y se expone a lo que en ella ocurre, se permiten relajaciones y desinhibiciones. "El diablo se mete a la casa por la puerta", así como se mete a lo sagrado del espacio resguardado por los estandartes. Se permite y se le permite moverse en la dualidad (sagrado/profano) y se queda sin embargo en ninguno de ellos, su posición es permanentemente transitiva.

Salir a la calle ese día de celebración es también salir a participar de la fiesta y de la diferencia social y étnica que se vive en Comitán. Es 
salir a observar a los "junitos o indios" como son llamados los tojolabales y campesinos de la región por los mestizos de la ciudad. Pero también es ver el carnaval y la relajación de estructuras que se hallan arraigadas en la sociedad comiteca. Es ver para "recordar" que soy diferente a los "junitos", para saberse más moderno e ilustrado en oposición a los tradicionales. Pero también es ver y recordar en el "disfraz" los valores propios. Es la sociedad teatralizada.

El disfraz alude las posiciones y jerarquías rígidas en la sociedad. Aunque puede ser un momento de catarsis social, este espacio sirve al final para señalar que todos allí (espectadores y participantes) tienen un lugar en la sociedad y que si bien, es el momento de saltarlos y de mofarse de esos lugares, jerarquías y conductas sociales, al final el orden se impone. Se estructura un espacio teatralizado para recrear estructuras y relaciones sociales reales. La ama de casa comiteca puede regocijarse en la gracia que le provoca su contraparte "carnavalizada" pero se sabe representada. Se permite salir a la calle para reconocerse en la dramatización y regresa de este drama para refugiarse en la realidad de la casa.

$\mathrm{El}$ ambiente social puede tener mil aristas según su espectador y participante, la simbolización de los roles sociales son tan diversos como ya hemos enunciado antes. Sin embargo, en suma todos en conjunto son formas reales o simbólicas de órdenes, valores y conductas sociales y culturales representadas o dramatizadas en un espacio.

\section{V}

Hemos intentado en este trabajo un recorrido y lectura etnográfica de un espacio en permanente negociación y reconstrucción. Hemos visto cómo la fiesta de san Caralampio, como ritual, escenifica o dramatiza relaciones sociales presentes en la sociedad (Leach, 1976; Turner, 1999). Hemos visto cómo las formas de apropiarse y percibir el espacio están estrechamente relacionadas con acontecimientos políticos, sociales, culturales y naturales. El espacio se construye, se apropia, se disputa y se percibe en una constante interacción naturaleza, cultura y sociedad. Esta interacción entre la naturaleza, la cultura y la sociedad en general es lo que los geógrafos denominan el "espacio vivido" o el "espacio socialmente construido" (Velásquez, 1997). En esta misma perspectiva entendemos que espacio es un "ámbito en permanente y cotidiana negociación entre actores, (es) un elemento que se redefine y conceptualiza de diversas formas, en estrecha vinculación con las relaciones sociales, los flujos económicos y las características físicas del territorio, pero también en las representaciones culturales de cada pueblo" (Hoffman y Salmerón, 1997:22).

En suma hemos visto en este trabajo que la representación simbólica que se construye sobre el espacio, se conceptualiza desde distintas maneras por distintos actores, posicionados a su vez desde distintos niveles de poder. Esta representación del espacio tiende a marcar fronteras interétnicas, a remarcar valores morales y culturales; es decir, tiende a producir diferencias y comuniones en un espacio de interconexiones. Encontramos que en un territorio, en un espacio, existen, al lado de formas de apropiación hegemónicas (Velásquez, 1997), espacios vividos desde la subalternidad que están en permanente redefinición, redefinición en la que los momentos y contextos históricos y políticos apor$\tan$ elementos relevantes. 


\section{Notas}

${ }^{1}$ Miel de azúcar con colorante.

${ }^{2}$ Las explicaciones ofrecidas por los participantes sobre esta disposición de los estandartes señalan que está asociada con la importancia en el calendario religioso de la obligatoriedad de los festejos de los santos. Así El Padre Eterno del municipio de La Trinitaria ocupa el lugar preeminente en el calendario religioso y el de mayor importancia en esta disposición, le sigue Santo Tomás del municipio de Oxchuc, san Bartolomé del municipio de Venustiano Carranza, todos en el estado de Chiapas, y finalmente les sigue san Mateo venido de Ixtatán en Guatemala, todos estos ocupan el lado derecho en el orden, por el lado izquierdo se ubican los demás estandartes simbolizando santos de menor importancia en la celebración dentro del calendario. Es preciso decir, que el santo celebrado el diez de febrero, san Caralampio, no tiene un estandarte pero es el suyo uno de los más importantes y concurridos festejos religiosos de la región. Otras explicaciones al respecto de la colocación de los estandartes, señalan la representación de los puntos cardinales, otras hablan de relaciones de parentesco entre los santos. Confesamos que es una vía que hemos explorado poco y que por ahora nos quedamos con la primera de las explicaciones. A reserva de abundar en ella, por ahora creemos que esta primera vía de explicación nos permite aventurar una interpretación más: la importancia de los festejos está asociada además, con las redes de comercialización y rutas de comercio y trabajo establecidas entre las poblaciones de la región.

${ }^{3}$ Sobre patrones y valores morales que rigen a algunas comunidades de la cañada tojolabal existe un proyecto de estudio llevado a cabo por el antropólogo Martín de la Cruz López, investigador del CESMECA.

${ }^{4}$ Cabe señalar que el cargo de músico — tamborero o piteroforma parte de esa estructura religiosa.

${ }^{5}$ El año 2001 ha sido el único en que hemos registrado a un mestizo de la ciudad representando al santo celebrado: san Caralampio. En esa ocasión éste se situó al frente del contingente.

${ }^{6}$ Existe otra mujer que participa en la celebración a san Caralampio, también mestiza y comiteca. Esta persona se encarga al momento en que arriban los "representantes religiosos" al templo de san Caralampio de dirigir una misa en honor al santo, además de recibir en su calidad de "encargada" del templo de san Caralampio, las limosnas que consigo traen los participantes de las comunidades y ejidos. Es notorio que aun cuando esta persona mantiene una "relación de hermandad" con los "junitos", no deja de tener calificativos hacia éstos como "tradicionalistas, inditos o junitos".

\section{Bibliografía}

Ascencio Cedillo, Efraín, 2000, “Tata Lampo: entre el pesimismo y la utopía”, en Paradoxas, suplemento cultural núm. 1, Abril de 2000, Tuxtla Gutiérrez, Chiapas.

Bourque, Nicole L, 1997, "Making Space: Social change, identity and the creation of boundaries in the Central Ecuadorian Andes", Bull. Latin. Amer. Res., vol. 16, núm. 2, pp. 153-167.

Da Matta, Roberto, 2002, Carnavales, malandros y héroes. Hacia una sociología del dilema brasileño. Fondo de Cultura Económica, México.

De la Fuente Fernández, Rosa, 2002, "Cartografía de la resistencia. Transformaciones del espacio social en Chiapas", Memoria, marzo, núm. 157, México, pp. 22-26.

Gómez Hernández, Antonio y Mario Humberto Ruz, 1992, Memoria baldía. Los tojolabales y las fincas. Testimonios, UNAMUNACH, México.

Hoffman, Odile y Fernando Salmerón Castro, 1997, Nueve estudios sobre el espacio. Representaciones y formas de apropiación, Ciesas y orstom, México.

Lameiras Olvera, José, 1998, "Impresiones literarias decimonónicas de lo festivo mexicano”, en Herón Pérez Martínez (editor), México en fiesta, El Colegio de Michoacán, Zamora.

Leach, Edmund, 1976, Sistemas politicos de la Alta Birmania, Anagrama, Barcelona.

Navarrete Carlos, 1990, Documentos históricos de la fiesta de San Caralampio, Instituto Chiapaneco de Cultura, Tuxtla Gutiérrez, Chiapas, México.

Ruz, Mario Humberto, 1992, Savia india, floracion ladina. Apuntes para una historia de las fincas comitecas (siglos XVIII y XIX), CONACUlTa, México. 
Solís Cruz, Jesús y Rosario Culebro Alfaro, 2002, "En el nombre del mártir San Caralampio. Espacios imaginados, espacios disputados", Memoria, marzo, núm.157, México, pp. 18-21.

Turner, Víctor, 1999, La selva de los símbolos, Siglo Veintiuno editores, México.
Velásquez H., Emilia, 1997, “La apropiación del espacio entre nahuas y popolucas de la Sierra de Santa Marta, Veracruz", en Hoffman, Odile y Fernando Salmerón Castro, 1997, Nueve estudios sobre el espacio. Representaciones y formas de apropiación, CIESAS y ORSTOM, México. 